\title{
Screening for the small-for-dates fetus: a two-stage ultrasonic examination schedule
}

\author{
J P NEILSON, C R WHITFIELD, T C AITCHISON
}

\section{Summary and conclusions}

To find an effective routine screening method for smallfor-dates fetuses 474 women with singleton pregnancies participated in a two-stage ultrasonic examination schedule. At the first-stage examination, which was conducted in early pregnancy, fetal crown-rump length or biparietal diameter was measured for an accurate assessment of gestational age, which was essential for interpreting the results of the second-stage examination. The second-stage examination was performed at 34-36 weeks and entailed measuring seven fetal variables, the results of which were assessed singly and in combination after delivery to identify the best indicator of small-fordates fetuses.

Fetal head measurements proved to be the least sensitive indicators of growth retardation, correctly identifying only 56-59\% of cases. Measurements of trunk area and circumference, however, correctly identified $81 \%$ and $83 \%$ of cases respectively, but the most effective screening index was the product of crown-rump length and trunk area: with this index 34 out of 36 small-fordates fetuses (94\%) were correctly identified.

Calculating the product of crown-rump length and trunk area from ultrasonic displays is quick and simple, and combined with the first-stage examination is a highly reliable screening method for small-for-dates fetuses.

\section{Introduction}

The Scottish Perinatal Mortality Survey for 1977 showed that 116 , or $11 \%$, of the perinatal deaths in singleton pregnancies during that year occurred in association with intrauterine growth

\footnotetext{
University Department of Midwifery, Queen Mother's Hospital, Glasgow G3 8SH

J P NEILSON, MB, CHB, research assistant

C R WHITFIELD, MD, FRCOG, professor

Department of Statistics, University of Glasgow, Glasgow G12 $8 Q Q$ T C AITCHISON, BSC, lecturer
}

retardation in the absence of fetal abnormality, maternal disease, and other complications of pregnancy. ${ }^{1}$ The majority of these deaths occurred in utero; $45 \%$ occurred after the 36 th week, and most of these could probably have been prevented by planned early delivery had the diagnosis of growth retardation been established in time. Similarly in Montreal Usher and $\mathrm{McLean}^{2}$ thought that up to $70 \%$ of perinatal deaths associated with intrauterine growth retardation might have been averted by the identification of all small-for-dates fetuses at 34 weeks. There is thus a vital need for an effective method of detecting such fetuses early enough to permit intensive biochemical and biophysical monitoring of the state of fetal wellbeing on which to base further management, including the timing and mode of delivery. This policy would attempt to anticipate the risk of intrauterine death and damage and be expected to result in improved perinatal mortality and morbidity and long-term outcome.

Abdominal palpation is not, however, an efficient method of identifying small-for-dates fetuses, the detection rate in most series being between $30 \%$ and $40 \%{ }^{3-5}$ Loeffler $^{6}$ reported that although prediction of birth weight by palpation was satisfactory when the fetus was of average size, its accuracy decreased at each extreme of the birth-weight range. He found that about $60 \%$ of predictions for babies weighing under $2300 \mathrm{~g}$ at birth had been inaccurate by over $450 \mathrm{~g}$, and in each case the predicted birth weight had been overestimated.

Additional strategies to improve the detection of intrauterine growth retardation have therefore evolved. The main approach is to define a group of pregnant women at high risk of bearing a small-for-dates infant so that intensive antenatal monitoring can be selectively implemented to identify those fetuses that are, in fact, growth retarded and guide subsequent management. The criteria used to define such high-risk groups are based on epidemiological factors, past reproductive performance, and the occurrence during the current pregnancy of complications known to be associated with growth retardation. Thus Adelstein and Fedrick ${ }^{7}$ developed a scoring system based on epidemiological data and past obstetric history, but when this was applied to 490 singleton pregnancies they found that $20 \%$ of primigravidas would have been identified as high risk but only $8 \%$ of this group were actually delivered of small-for-dates infants, and that as many as $54 \%$ of small-for-dates babies in the primi- 
gravid group were born to "low-risk" mothers. Though the scoring system was rather better in parous patients, it was concluded that the approach was not effective. Our experience in applying a list of risk criteria (epidemiological, past and current obstetric complications, clinically suspected intrauterine growth retardation) to the first 500 women to be delivered in this hospital during 1977 was broadly similar. We found that $16 \%$ of these patients would have had to be included in the high-risk group to identify $43 \%$ of small-for-dates babies, or, with less strict criteria, $23 \%$ would have been selected to identify $58 \%$ of such infants. ${ }^{5}$

Serial ultrasonic cephalometry may identify up to $73 \%$ of small-for-dates fetuses ${ }^{8}$ but is not practicable as a routine screening method in all pregnancies. Ultrasonic measurement of other fetal dimensions has been described, and, with recognition of the "brain-sparing" phenomenon which may be associated with intrauterine growth retardation, ${ }^{9}$ attention has focused on measurement of the fetal trunk to provide evidence of growth retardation at an earlier stage than would be possible by cephalometry. ${ }^{1011}$ After an encouraging initial evaluation of the accuracy of several measurements as indicators of the smallfor-dates fetus ${ }^{4}$ we now report a study aimed at developing an effective means of routine screening for such fetuses by a twostage ultrasonic examination schedule.

\section{Patients and methods}

We studied 474 patients with singleton pregnancies. Of these, 90 $(19 \%)$ had been referred for serial ultrasonic cephalometry because of past or present obstetric complications; the remainder were lowrisk volunteers from the antenatal clinic. At any single session all patients attending the clinic at between 34 and 36 weeks of gestation were asked to co-operate in the study, and fewer than $10 \%$ declined. All had undergone ultrasonic examination at their first attendarice at the antenatal clinic (in accordance with established hospital policy), when gestational age was assessed from the fetal crown-rump length (up to 14 weeks) ${ }^{12}$ or the biparietal diameter (from 13 weeks). ${ }^{13}$ Measurements were carried out in the antenatal clinic by a specially trained midwife or obstetrician using a real-time scanner (System 85 Diagnostic Sonar, Livingstone, Scotland). When a discrepancy was found between the ultrasonic and clinical assessments of gestational age the examination was repeated with a conventional static scanner in the diagnostic ultrasound unit and the result accepted as the definitive indicator of gestational age. In the patients studied the mean gestational age at the time of this first-stage examination was 15 weeks (34\% of the examinations being carried out before 14 weeks, $91 \%$ before 20 weeks, and all before 28 weeks).

At the second-stage ultrasonic examination, carried out between 238 days ( 34 weeks) and 255 days ( 36 weeks 3 days), the following seven variables were measured: biparietal diameter, head area, head circumference, trunk area, trunk circumference, transverse trunk diameter, and crown-rump length. Biparietal diameter was measured by the combined $\mathrm{A}$ and $\mathrm{B}$ mode technique described by Campbell, ${ }^{14}$ and head area and circumference from a transverse ellipsoid section of the fetal head displaying a central midline echo (falx cerebri) with a short double echo (third ventricle) one-third of the distance from the sinciput. ${ }^{15}$ Area, circumference, and transverse diameter of the trunk were measured on a transverse section of the fetal trunk at right angles to the long axis of the aorta and displaying a short segment of umbilical vein $^{10} 11$ (fig 1). Transverse diameter was measured on the bistable display using electronic callipers calibrated to a velocity of $1600 \mathrm{~m} / \mathrm{s}$. Crown-rump length (fig 2) was measured on a longitudinal section of the fetus that included both the fetal bladder and the maximum area of the fetal head; no allowance was made for flexion of the fetal trunk. A semi-automated electronic measuring device ${ }^{16}$ was used for accurate and rapid measurement (direct from the grey-scale image) of area and circumference variables and crown-rump length. All measurements were carried out by one of us (JPN) with a conventional static scanner (Diasonograph 4102, EMI/Nuclear Enterprises, Edinburgh).

In 57 cases $(12 \%)$ satisfactory fetal head measurements could not be obtained, either because the head was in a direct occipitoanterior or occipitoposterior position or because it was low in the maternal pelvis. Trunk area and circumference were measured in all cases, though occasionally the fetal stomach was used as a marker for the correct section when acoustic shadowing behind an anteriorly positioned fetal spine did not permit visualisation of the umbilical vein. The crown-

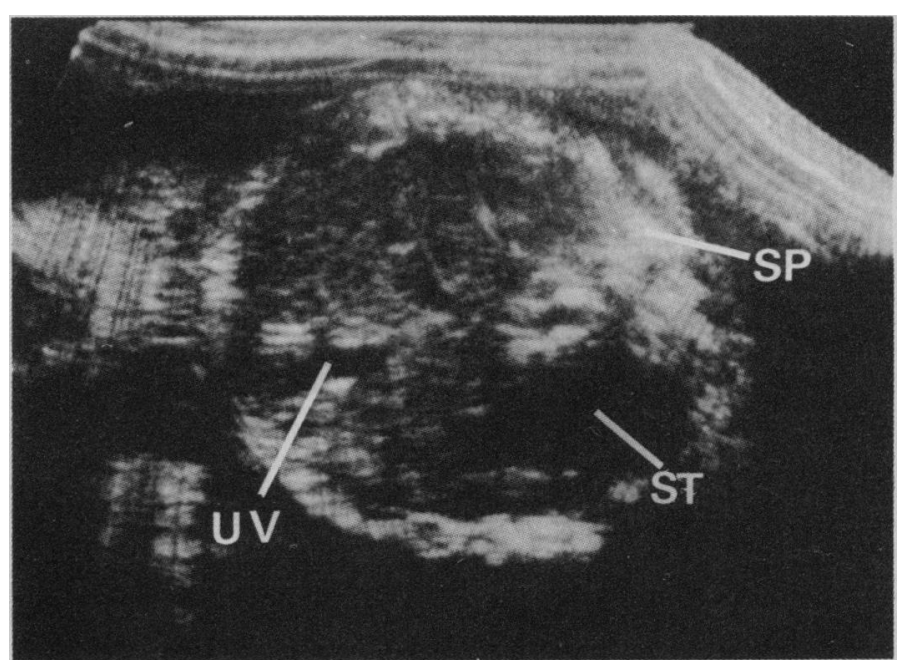

FIG 1 -Transverse section of fetal trunk. UV $=$ Umbilical vein. $S P=$ Fetal spine. ST = Fetal stomach.

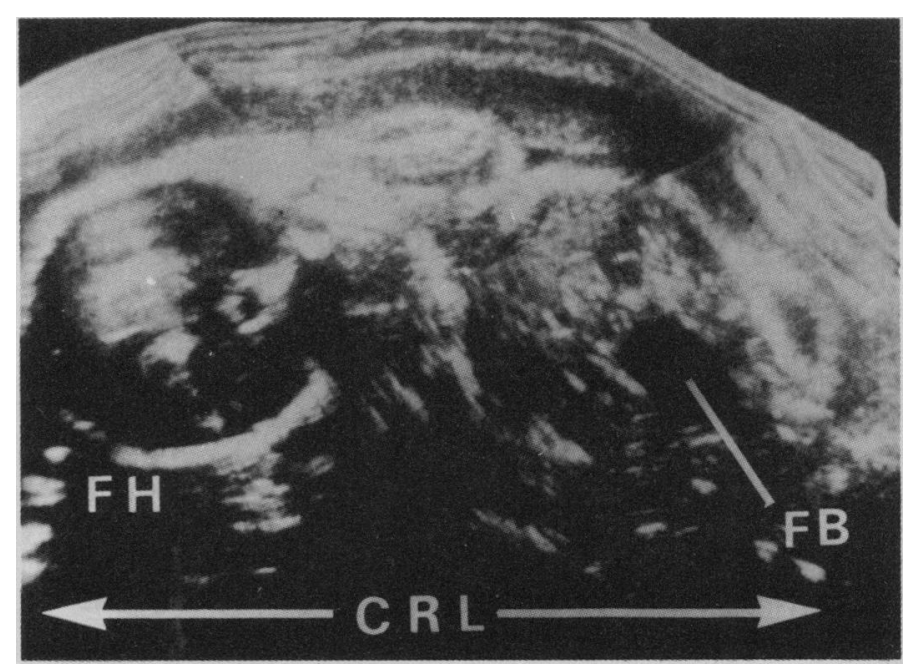

FIG 2-Longitudinal section of fetus (breech presentation). $\mathrm{FH}=$ Fetal head. $\mathrm{FB}=$ Fetal bladder. $\mathrm{CRL}=$ Crown-rump length.

rump length was also measured in all cases, a low fetal head being no obstacle to accurate measurement.

After delivery the measured variables were analysed singly and in combination to identify the optimal index for detecting small-fordates fetuses. For this purpose nomograms were constructed by plotting for each variable the measurements obtained from the babies of normal birth weight-that is, above the 5th percentile-against gestational age at the time of examination. Median, 10th, and 90th percentile curves were constructed by plotting the appropriate values for each of the eight consecutive two-day periods between 238 and 255 days, and a smoothed percentile curve was obtained by carrying out a weighted least-squares analysis of the logarithms of the percentiles against time (the appropriate weights being the number of observations of the variable in the relevant two-day period). Measurements obtained from the small-for-dates fetuses were then plotted and falsepositive and false-negative rates calculated for each variable, the 10 th percentile curve on the nomograms being used as an arbitrary demarcation line for identifying small-for-dates fetuses. Thus a false-positive result was recorded when the birth weight was normal though the measurement was below the 10th percentile curve, and a false-negative result recorded when the baby was small for dates though the measurement was above this demarcation line.

\section{Results}

Of the 474 patients, 36 were delivered of infants with birth weights below the 5 th percentile of the Aberdeen chart of Thomson et al, ${ }^{17}$ 
and these were classified as small for dates. The mean birth weight in this group was $2310 \mathrm{~g}$ (range 1200-2770 g) and it included two stillborn infants (both fresh), one of which was the only malformed infant in the series (renal agenesis). Of the 36 small-for-dates fetuses, 18 had not been suspected clinically as being small for dates at any time, 17 were identified by abdominal palpation as small for dates, and in one case elective serial cephalometry provided evidence of growth retardation despite a clinical impression of normal growth.

The table gives the results for the different variables measured at the second-stage examination. The head measurements (biparietal diameter, area, and circumference) were inefficient screening examinations since they identified only $56-59 \%$ of the small-for-dates fetuses. In contrast, measurements of trunk area and circumference correctly identified $81 \%$ and $83 \%$ of cases respectively, though transverse trunk diameter, with a detection rate of $61 \%$, was no more useful than the head measurements.

Results of measuring different variables at second-stage ultrasonic examination

\begin{tabular}{lccc}
\hline \multicolumn{1}{c}{ Variable } & $\begin{array}{c}\text { Detection of } \\
\text { small-for- } \\
\text { dates fetuses } \\
(\%)\end{array}$ & $\begin{array}{c}\text { False- } \\
\text { negative } \\
\text { results } \\
(\%)\end{array}$ & $\begin{array}{c}\text { False- } \\
\text { positive } \\
\text { results } \\
(\%)\end{array}$ \\
\hline Biparietal diameter & 58 & 42 & 10 \\
Head area & 59 & 41 & 10 \\
Head circumference & 56 & 44 & 8 \\
Trunk area & 81 & 19 & 11 \\
Trunk circumference & 83 & 17 & 10 \\
Transverse trunk diameter & 61 & 39 & 12 \\
Crown-rump length & 69 & 31 & 12 \\
Crown-rump length $\times$ trunk area & 94 & 6 & 12 \\
Crown-rump length $\times$ circumference & 89 & 11 & 9 \\
Head area/trunk area & 44 & 56 & 9 \\
\hline
\end{tabular}

In two of the 36 cases satisfactory head measurements were not obtained.

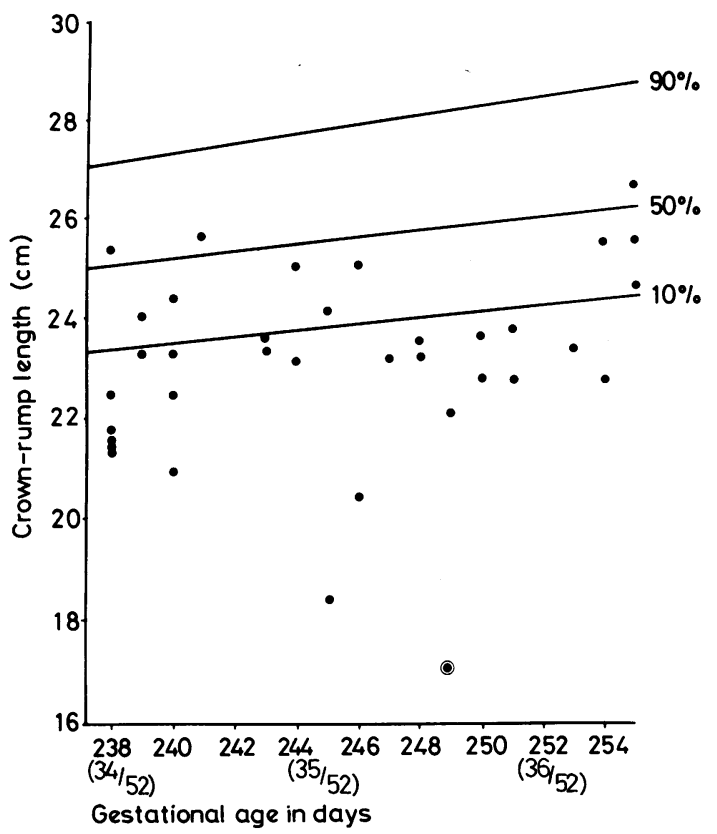

FIG 3-Percentile curves for crown-rump length. Points represent measurements obtained from small-for-dates fetuses. (In the case of renal agenesis (encircled point) fetal bladder not identified before measurement of crown-rump length.)

Though the crown-rump length measurement failed to identify $31 \%$ of affected fetuses (fig 3) and the trunk area measurement failed to identify $19 \%$ (fig 4), the product of these measurements gave a falsenegative rate of only $6 \%$ and failed to identify only two of the 36 affected fetuses (fig 5). The false-positive rate obtained with this index was $12 \%$; and of these cases, $48 \%$ related to babies with birth weights below the 10th percentile though greater than the 5 th percentile. The product of crown-rump length and trunk area provided the optimal means of screening for the small-for-dates fetus, being more efficient than any single measurement or any other (usually more complex) combination of measurements. It was also much more useful

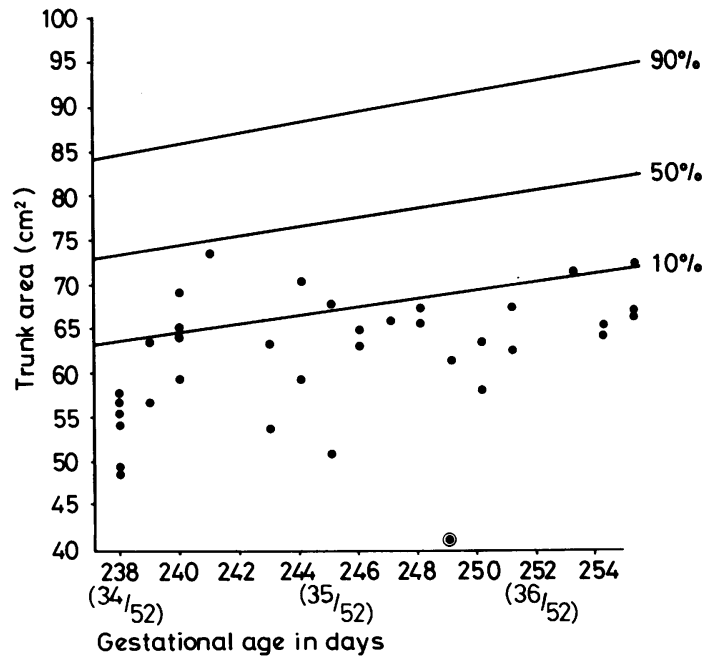

FIG 4-Percentile curves for trunk area. Points represent results obtained from small-for-dates fetuses. Encircled point $=$ case of renal agenesis.

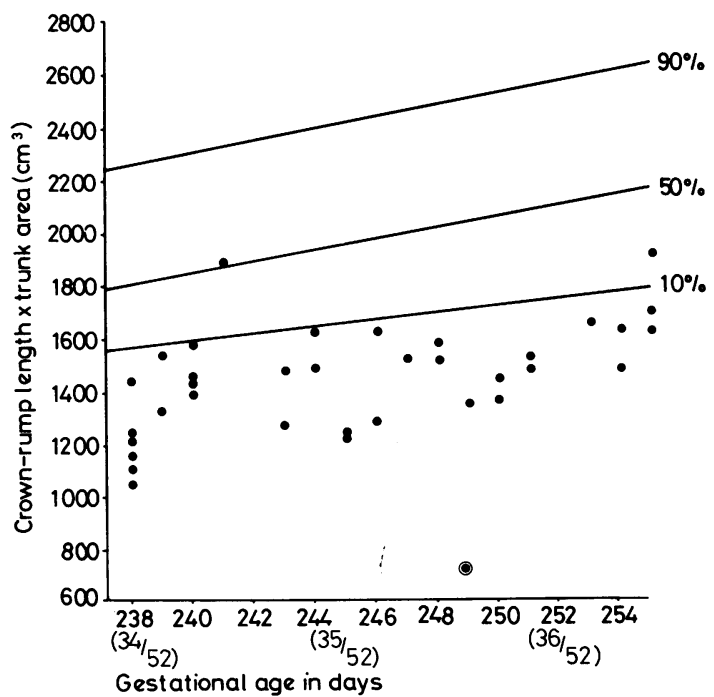

FIG 5-Percentile curves for product of crown-rump length and trunk area. Points represent results obtained for smallfor-dates fetuses. Encircled point = case of renal agenesis.

than ratios of head area and trunk area measurements, ${ }^{18}$ which gave high false-negative rates.

\section{Discussion}

The screening procedure described here comprises a twostage ultrasonic examination schedule, an accurate knowledge of gestational age being essential to permit interpretation of the second-stage examination result. Major errors may occur in the clinical estimation of gestational age, even in the first trimester, ${ }^{10}$ and routine scanning of all patients at their first hospital visit is therefore important for assessing gestational age at a time when ultrasonic examination is most accurate. ${ }^{1320}$ With the advent of the real-time scanner this procedure may be assimilated easily into the smooth running of the antenatal clinic and provides much other valuable information. The timing of the second-stage examination at 34-36 weeks also merits comment. At any gestational age fetuses of similar size may be growing, and thereafter continue to grow, at different rates. Hence if any measurement has validity as an index of fetal size its accuracy in predicting birth weight and identifying small-for-dates fetuses increases as 
the time interval between measurement and delivery decreases. On the other hand, the clinical usefulness of the information in providing early warning of intrauterine growth retardation decreases as pregnancy advances. The chosen time of 34-36 weeks is therefore a compromise between efficiency in detecting smallfor-dates fetuses and the usefulness of the information provided.

As second-stage variables the head measurements were generally less efficient than the trunk measurements, reflecting the brain-sparing effect in which brain weight is relatively less diminished than liver weight in small-for-dates fetuses. ${ }^{9}$ Transverse trunk diameter, however, was less efficient than the other trunk measurements; in small-for-dates fetuses the transverse trunk section is often distorted from the usual near-circular shape and may be elongated in either the anteroposterior or transverse plane. With transverse elongation of the trunk the diameter may be within normal limits despite reduced trunk area and circumference. The product of crown-rump length and trunk area or circumference was a more sensitive index than any single trunk variable we measured. Small-for-dates infants often have shorter body lengths, ${ }^{2}$ and measurement of the direct crown-rump length is also of value in aiding detection of the hyperflexed small-for-dates fetus. In addition, flexion of the fetal trunk not only decreases the crown-rump length but increases the dimensions of the measured transverse section, so that a combination of length and cross-sectional area provides a better assessment of fetal size. Because false-negative results are of greater significance than false-positive results the product of crown-rump length and trunk area was a more useful index than the product of crownrump length and trunk circumference, which was associated with a slightly higher false-negative rate. Calculation of the first index is suitable as a screening procedure, being simple and quick to execute using electronicarea- and perimeter-measuring devices (which are becoming available commercially). The entire examination, including plotting of the result and explanation to the mother, takes no more than four minutes.

We conclude that this two-stage ultrasonic examination schedule to assess gestational age at the first clinic visit and assess fetal size at 34-36 weeks by determining the product of crown-rump length and trunk area is highly effective in identifying the small-for-dates fetus. The schedule is suitable as a screening procedure and is fully consistent with the philosophy of antenatal care that risk is better assessed by investigation of the individual fetus than by epidemiological considerations. ${ }^{21}$ The $12 \%$ false-positive rate must not be ignored, however, since an erroneous diagnosis that the fetus is small for dates may lead to inappropriate intervention. We are therefore now conducting a randomised controlled trial to assess both the effect on fetal outcome and obstetric management of instituting this screening programme and the efficacy of the index prospectively.

This study was supported by a project research grant from the
Medical Research Council, for which we express our thanks. We also acknowledge the contributions of Drs H P Robinson and B K Wittmann in laying the foundations of this research, and the technical work of Messrs J E E Fleming and A J Hall.

\section{References}

1 Mcllwaine GM, Howat RCL, Dunn F, Macnaughton MC. The Scottish Perinatal Mortality Survey. $\mathrm{Br}$ Med $\mathcal{f} 1979$;ii :1103-6.

2 Usher RH, McLean FH. Normal fetal growth and the significance of fetal growth retardation. In: Davis JA, Dobbing J, eds. Scientific foundations of paediatrics. London: Heinemann, 1974:69-80.

- Campbell S. Physical methods of assessing size at birth. In: Ciba foundation symposium 27: size at birth. Amsterdam: Associated Scientific Publishers, 1974:275-93.

- Wittmann BK, Robinson HP, Aitchison T, Fleming JEE. The value of diagnostic ultrasound as a screening test for intrauterine growth retardation: comparison of nine parameters. Am $\mathcal{f}$ Obstet Gynecol 1979; 134:30-5.

- Neilson JP. Ultrasonic screening for fetal growth retardation. Perinatology/ Neonatology $1979 ; 3: 42-7$

- Loeffler FE. Clinical foetal weight prediction. Br f Obstet Gynaecol $1967 ; 74: 675-9$.

7 Adelstein P, Fedrick J. Antenatal identification of women at increased risk of being delivered of a low birth weight infant at term. Br f Obstet Gynaecol 1978;85:8-11.

- Campbell S, Dewhurst CJ. Diagnosis of the small-for-dates fetus by serial ultrasonic cephalometry. Lancet 1971 ;ii : 1002-6.

- Gruenwald P. Pathology of the deprived fetus and its supply line. In: Ciba foundation symposium 27: size at birth. Amsterdam: Associated Scientific Publishers, 1974:3-19.

${ }^{10}$ Campbell S, Wilkin D. Ultrasonic measurement of fetal abdomen circumference in the estimation of fetal weight. Br f Obstet Gynaecol 1975;82: 689-97.

${ }^{11}$ Hansmann M. Measurements of fetal age, growth and nutrition. In: Beard RW, Campbell S, eds. The current status of fetal heart rate monitoring and ultrasound in obstetrics. London: Royal College of Obstetricians and Gynaecologists, 1977: 165-89.

12 Robinson HP. Sonar measurement of fetal crown-rump length as means of assessing maturity in first trimester of pregnancy. $\mathrm{Br}$ Med $\mathcal{F} 1973$;iv: 28-31.

18 Campbell $\mathrm{S}$. The prediction of fetal maturity by ultrasonic measurement of the biparietal diameter. Brf Obstet Gynaecol 1969;76:603-9.

14 Campbell S. An improved method of fetal cephalometry by ultrasound. Br $\mathcal{O}$ Obstet Gynaecol 1968;75:568-76.

16 Campbell S, Thoms A. Ultrasound measurement of the fetal head to abdomen ratio in the assessment of growth retardation. $\mathrm{Br} \mathcal{F}$ Obstet Gynaecol 1977;84:165-74.

${ }^{16}$ Fleming JEE, Hall AJ, Robinson HP, Wittmann BK. Electronic area and perimeter measurement of ultrasonic images. $₹ C U$ 1978;6:379-84.

17 Thomson AM, Billewicz WZ, Hytten FE. The assessment of fetal growth Brf Obstet Gynaecol 1968;75:903-16.

${ }^{18}$ Varma TR, Taylor $\mathrm{H}$, Bridges $\mathrm{C}$. Ultrasound assessment of fetal growth Br F Obstet Gynaecol 1979 ;86:623-32.

10 Beazley JM, Underhill RA. Fallacy of the fundal height. Br Med f 1970; iv:404-6.

${ }^{20}$ Robinson HP, Fleming JEE. A critical evaluation of sonar "crown-rump length" measurements. Br $\mathcal{f}$ Obstet Gynaecol 1975;82:702-10.

${ }^{21}$ Leading article. Rethinking antenatal care. $\mathrm{Br} M e d f$ 1978;ii:1177-8.

(Accepted 19 February 1980)
ONE HUNDRED YEARS AGO The large number of springs in the Duchy of Nassau has been increased by the opening of the Assmannshausen spa in May 1879. It is situated in one of the most beautiful parts of the Rhine country, on the right bank, near Rudesheim, just beneath the rocks and beautiful woods of the Niederwald, from which, looking in the direction of Maintz, the river expands into the proportions and aspect of a beautiful mountain-lake. Assmannshausen is well protected by the rocks from high winds, while the Rhine, which at this point is very swift, brings to it a constant current of fresh pure air, which cools the summer heats. The springs have been known from the middle ages; but the work of perfect restoration has only been begun during the last seven years. The handsome bathing establishment stands in its own grounds. The garden extends to the river bank, and just opposite is the beautiful old castle of the Rheinstein. Every social comfort and amusement is provided in the house, and private accommodation can be had in the village. Dr H Mahr, the medical director, lives on the spot during the season for the purpose of advising the visitors in the use of the baths. The water contains a large amount of carbonate of lithium; and, according to Professor Fresenius, is likely to obtain a high place among alkaline thermal springs, and a reputation for all those diseases for which treatment by this kind of mineral water is advantageous. A litre of the water contains, on the average, three centigrammes of carbonate of lithium. Great claims are put forth for the Assmannshausen water-especially for its beneficial action on the mucous membrane of the digestive and respiratory tracts, and on the secretions of the kidneys and skin, as well as on effusions into the joints depending on the gouty diathesis. The best season is during the summer months; and visitors have the advantage of the varying scenery of the great river, of delightful inland excursions, and proximity to a great number of places of interest. Assmannshausen is for many reasons a place well worthy of a visit, not the least of which is the excellent red wine of the district. (British Medical fournal, 1880.) 